\title{
Resistance to Customer-driven Business Model Innovations: An Explorative Customer Experience Study on Voice Assistant Services of a Swiss Tourism Destination
}

\author{
By Anna Victoria Rozumowski* , Wolfgang Kotowski ${ }^{ \pm}$\& \\ Michael Klaas
}

\begin{abstract}
For tourism, voice search is a promising tool with a considerable impact on tourist experience. For example, voice search might not only simplify the booking process of flights and hotels but also change local search for tourist information. Against this backdrop, our pilot study analyzes the current state of voice search in a Swiss tourism destination so that providers can benefit from those new opportunities. We conducted interviews with nine experts in Swiss tourism marketing. They agree that voice search offers a significant opportunity as a new and diverse channel in tourism. Moreover, this technology provides new marketing measures and a more efficient use of resources. However, possible threats to this innovation are data protection regulation and providers' lack of skills and financial resources. Furthermore, the diversity of Swiss dialects pushes voice search to its limits. Finally, our study confirms that tourism destinations should cooperate to implement voice search within their touristic regions. In conclusion, following our initial findings from the sample destination, voice search remains of minor importance for tourist marketing in Switzerland as evident in the given low use of resources. Following this initial investigation of voice search in a Swiss tourism destination, we recommended conducting further qualitative interviews on tourists' voice search experience in different tourist destinations.
\end{abstract}

Keywords: Business model innovation, resistance to innovation, customer experience, tourism marketing, voice search, Swiss destination marketing, destination management

\section{Introduction}

Since innovations like big data and machine learning have already caused lasting changes in the interaction between companies and consumers (Shankar et al. 2010), interconnection and automation enable the autonomous decision-making of technical systems under the term "Internet of Things." This "fourth industrial revolution" (Tussyadiah 2020) has new, in part hardly foreseeable, consequences for marketing and especially for customer experience management. To contribute to the understanding of this profound disruption, this study deals with voice assistants as part of the Internet of Things and their influence on marketing (Pagani

${ }^{*}$ Research Associate, ZHAW Zurich University of Applied Sciences, Switzerland.

${ }^{ \pm}$Project Manager, ZHAW Zurich University of Applied Sciences, Switzerland.

${ }^{*}$ Head, Department of Digital Marketing, ZHAW Zurich University of Applied Sciences, Switzerland. 
et al. 2019). These systems enable new services, such as voice search, which allow new customer experiences. "Voice search is the technology that enables users to access information using spoken queries" (Li et al. 2009, p. 769). Using an example of these services' innovation diffusion in Swiss tourism by investigating a sample destination, this study shows how companies react to this contemporary disruption.

Natural language processing and voice recognition processes are increasingly sophisticated, as they can rely on more advanced computing power and algorithms (Hirschberg and Manning 2015, Hoy 2018). For example, voice assistants not only play music, order products from an online shop, or make phone calls (Saad et al. 2017) but also independently perform complex tasks such as setting appointments with a hairdresser without being recognized as a computer system by their human counterpart (Kreutzer and Sirrenberg 2020). This increasingly better quality of processes makes these services valuable to consumers and accessible through products such as Apple's Siri, Google Home, or Amazon's Alexa (Kumar et al. 2020). A voice assistant is not bound to hardware like Amazon's Echo Dot. An app on a smartphone or even on a notebook with low computing power is sufficient, as they only establish a connection to a powerful server via the Internet where the actual service is running.

As voice assistants support consumers in many daily tasks (Kreutzer \& Sirrenberg 2020, Lee and Choi 2017), they are increasingly replacing smartphones with which these tasks have previously been performed using text input (Schalkwyk et al. 2010). About $70 \%$ of users in the United States are using voice assistants more frequently to search for something (McCaffrey et al. 2018). Therefore, the total number of voice assistance users is growing steadily. Moreover, new consumer groups such as blind people (Barata et al. 2018) and children (Lovato and Piper 2019) are using these services with rising demand, whereby children are socialized at an early age to use them. A Swiss study showed that one-third of the Swiss population is already using voice functions mainly via smartphone (Kunath et al. 2019). People use voice search mainly to retrieve information (e.g., weather data) followed by navigating and localizing (Kunath et al. 2019). As a result, revenues of USD 27.8 billion are expected from the sale of such devices (IDC 2018). Moreover, revenues of more than USD 40 billion are expected from shopping using voice assistants in the United States and the UK by 2022 (Perez 2018).

However, despite these impressive figures of consumption, voice marketing is relatively underdeveloped, for instance, concerning the use of certain search terms (Kreutzer and Seyed Vousoghi 2020). Moreover, consumer and marketing research on voice assistants and their usage is still at an early stage. For example, a common theoretical framework is missing (Cecchinato and Harrison 2017, Purington et al. 2017), which is surprising as voice assistants provide new customer touchpoints that enable new customer experiences (Kreutzer and Seyed Vousoghi 2020). Therefore, this pilot study's general purpose (Smith 2019) is to contribute to the understanding of the customer experience using voice assistants.

Studies on consumer interaction with voice assistants are still rare (Rhee and Choi 2020, Rzepka 2019) although some have focused on text-based chatbots (e.g., Hill et al. 2015, Von der Pütten et al. 2010). Moreover, as far as customer 
experience is concerned, previous studies assume that all senses of the consumer are stimulated (Pagani et al. 2019). However, this must be questioned in the case of voice assistants because of restrictions such as the lack of image representation (Carmel 2019, Mari 2019). Thus, the individual interaction of a consumer with a voice assistant still requires considerable research (Liu et al. 2017).

To contribute to closing these research gaps in marketing and consumer research, the investigation of voice assistants in tourism, especially in hotels, is a suitable use case (Kattara and El-Said 2014). For example, there are first applications in hotels (Amazon 2020, Lodging Magazine 2016), and consumers could be observed along the entire touristic customer journeys (Esser 2019). The potential and effects of customer interaction automation by voice assistants could be investigated (Ivanov and Webster 2019a, 2019b). The creation of new customer journeys, which leads to new customer experience, is a central object of such research (Tussyadiah 2020). These new customer experiences are new social phenomena, which is why such studies should focus not only on technical but also sociocultural aspects (Russell et al. 2015), which gain relevance with the emergence of those innovations.

To begin this research program, the general investigation of hotels is a good way to start as they provide the context in which consumers interact with voice assistants during vacations. For example, by providing devices such as Amazon's Echo Dot in hotel rooms, hotels offer their guests the opportunity to continue consuming services that they are accustomed to at home. By providing content such as information about the hotel or the destination (Bowen and Morosan 2018, Hörner 2019), hotels can also investigate how their guests respond to these offers and how they use the voice assistants. Thus, the influence of voice assistants on branding (Ho and Bodoff 2014, Kang et al. 2016, Tam and Ho 2005) could be studied.

Surprisingly, however, it became apparent at the beginning of this pilot study that the provision of such innovative service by hotels remains rare despite initial practical exceptions. Consumer acceptance of this new technology, and accordingly innovation diffusion, is intensive as they recognize its usefulness and ease of use (Klaus and Zaichkowsky 2020, Wirtz et al. 2016). In contrast, resistance to innovation otherwise normally observable among consumers (Bagozzi and Lee 1999) and especially barriers to the adoption of smart services (Hong et al. 2020) are, in this case, present among hotel managers (Kattara and El-Said 2014). This is unusual as the introduction of innovative products and services is particularly essential for companies' success (Prins and Verhoef 2007).

Therefore, as a first step, this pilot study will examine the interplay of these extremely different innovation diffusions on the part of consumers and hotels. For this purpose, the responsible managers of a vacation destination, hotel and experts in tourism and marketing were interviewed, all dealing with the diffusion of innovations in hospitality. Hence, the specific purpose of this research program is to investigate how touristic destinations use voice assistants as an innovation and thereby provide a customer voice experience for their member hotels' guests. This pilot study contributes to this research program by investigating the given managerial context, technological realities, and innovation conditions. Such 
knowledge paves the way to understanding how value is created in the tourist customer journey through consumer interaction and business innovations with voice assistants and how the customer experience is hereby defined.

The remainder of this article discusses innovation diffusion theory and value cocreation. Here, value cocreation does not refer to the direct interaction between consumer and voice assistant but rather to the interaction between a hotel as a provider of a voice assistant and its guests. The theory of business model innovation (BMI) serves as a theoretical lens to examine the reactions of tourism providers to innovation in the consumption of their guests to identify the foundation for voice marketing. The following sections present methods of data collection and analysis, as well as results and implications for research on voice marketing and consumer voice experience.

\section{Literature Review}

This section discusses innovation diffusion theory. This theory deals with processes of diffusion and adoption of ideas, process flows, and other objects and content that are new to involved individuals and groups. Innovations affect the creation of value, and as new ideas and processes, they offer new resources and approaches to its cocreation. For companies, these innovations accordingly imply that they must adapt to environmental changes by changing their business model. By doing so, they can continue to cocreate value with customers and thus continue to exist (Keiningham et al. 2019). This section, therefore, discusses innovation diffusion theory in conjunction with the theories of value cocreation and BMI. Theoretical focus is placed on the critical incident when a company rejects an innovation on the side of consumers. This new theoretical perspective provides a theoretical lens for investigating coping strategies of companies that reject innovations or at least do not want to contribute directly to their diffusion.

From a historical perspective, multiple disciplines deal with innovation diffusion theory. For example, anthropologists and ethnologists study the cultural development of social groups (Boas 1942), and sociologists study the spread of new technologies - such as new crops in agriculture (Ryan and Gross 1943). Moreover, in the present, marketing and consumption research deal with the adoption of new products (Ma et al. 2014). The Bass diffusion model, conceptualized by Bass (1969), describes this process as having four elements: innovation, time, communication channels, and a social system (Mahajan 2010). Something is an innovation as long as it is new to an individual (Mahajan 2010). Over time, this innovation is diffused into the individual's social system through communication channels so that the innovation is eventually no longer new for the members of the social system and thus loses its innovative character.

In addition to this process and its development, innovation diffusion theory also distinguishes the actors involved in disseminating innovations into innovators and imitators (Omerzel 2016, Van den Bulte and Joshi 2007). A popular assumption of this model and innovation diffusion research in general is that innovators successfully select innovations (Google Data, U.S., Google App 2016). 
However, this assumption ignores the fact that companies also choose unsuccessful innovations that do not help them create value or even destroy value or that companies reject potentially successful innovations (Biondi and Bracci 2018). However, these reactions are the focus of this study.

The adoption and implementation of innovations are of existential importance for companies; otherwise, their competitors will force them out of the market (Drucker 2001). Companies such as Apple or Xerox, which have shifted their central value creation from the manufacture of computers and photocopiers to the provision of media and services (Ivan 2008), have been able to respond to innovations in their markets through BMI. However, this adjustment only occurred after conflicts arose in the application of their former business models and after the deterioration or failure of the value cocreation process with consumers (Amit and Zott 2001). These conflicts result from different barriers that companies have to overcome in their BMI (Chesbrough 2010). Studies on these barriers show different reasons such as an unfavorable allocation of resources that do not stimulate innovations (Gold 2018), a lack of innovation-oriented leadership (Chesbrough 2010), a lack of understanding change in terms of sense-making (McDermott and O'Connor 2002), or a generally strong attachment to logics of their current market so that companies cannot question these given market logics without criticizing themselves (Chesbrough and Rosenbloom 2002).

With the emergence of service-dominant logic in marketing (Vargo and Lusch 2004), consumer engagement is gaining attention as part of the value creation process (Payne et al. 2008). Products and services, such as IKEA furniture or vacations, only gain value for consumers through the experience they create together with the company that is offering these products and services. In this experience-oriented value creation process (Chandler and Lusch 2015), value is an interactive experience in which the experience of emotions, contexts, and symbols is emphasized (Arnould and Thompson 2005). The consumer experience process is divided into different encounters, also called touchpoints between companies and consumers, at which the value cocreation process between companies and consumers takes place (Payne et al. 2008).

On the consumer side, this value cocreation process can change if they, but not the companies, adopt innovations. This changes the environment for companies, that is, the context of value cocreation (Brozovic 2018). Due to cultural and technical changes, however, innovations are constantly occurring on the consumer side, which is why companies would have to react flexibly to these innovations (Hughes and Morgan 2007). Only in this way will they be able to keep their business models aligned with customer experiences and thus avoid losing touch with their customers and their needs (Keiningham et al. 2019).

However, companies reject innovations in some situations mentioned above (Biondi and Bracci 2018). The implications of such rejections for the business model and especially for value cocreation and consumer experience are still theoretically and empirically under-researched. Recent contributions (Keiningham et al. 2019, Libai et al. 2009) explain the interaction between customer experience, innovation diffusion, and BMI. Nevertheless, the critical incident of a company's rejection of an innovation remains unexplored. Therefore, this study aims to close 
this research gap. Moreover, the empirical focus on tourism consumption allows this study to contribute to the stream of research on tourism innovation (Maggioni et al. 2014, Pikkemaat et al. 2019), which has also ignored this critical incident.

\section{Methodology}

To understand how value is created in the touristic customer journey, we conducted nine semi-structured qualitative interviews. The study aims to analyze current and planned interactions with voice assistants in the tourism industry.

\section{Research Design}

If relevant information is lacking and the nature of a (research) problem is unclear (Stebbins 2001), exploratory qualitative research is particularly appropriate to fill this gap (Belk et al. 2013). Especially when research is on product innovations or marketing decisions, meaningful insights are gained through such an approach (Belk et al. 2013, Weis and Steinmetz 2012). Moreover, qualitative research is used to deepen the understanding of each concept being analyzed within the study (Silverman 2020). Table 1 summarizes the study's research design.

Table 1. Research Design Overview

\begin{tabular}{|l|l|}
\hline Research focus & $\begin{array}{l}\text { The use and application of voice search in } \\
\text { a Swiss tourism destination organization }\end{array}$ \\
\hline Sample & $\begin{array}{l}\text { Nine tourism and marketing experts from } \\
\text { a Swiss tourism destination (Table 2) }\end{array}$ \\
\hline Data collection & $\begin{array}{l}\text { Semi-structured guided interviews with } \\
\text { experts }\end{array}$ \\
\hline Data analysis & $\begin{array}{l}\text { Qualitative content analysis based on } \\
\text { Mayring (2000) and Schreier (2014) }\end{array}$ \\
\hline
\end{tabular}

Expert interviews are defined by the experts themselves and not by a specific approach (e.g., narrative interview) (Flick 2010, Rabionet 2011, Trinczek 2009). The objective of the interviews is to systematically gather information on the nature of the research object, where the experts share their profound knowledge (Trinczek 2009).

Sample

This study focuses on a vacation destination in Switzerland. The experts in the field of digitization and marketing in tourism are composed of the following: 
Table 2. Overview Sample

\begin{tabular}{|c|c|}
\hline Tourism destination organizations & $\begin{array}{l}\text { - } 1 \text { destination manager (Expert 1) } \\
-\quad 1 \text { marketing and communication } \\
\text { manager (Expert } 2 \text { ) }\end{array}$ \\
\hline Tourism digitization agency & $\begin{array}{l}2 \text { founders of tourism digitization } \\
\text { agencies (Expert 3) and (Expert 4) }\end{array}$ \\
\hline Touristic leisure provider & $\begin{array}{l}\text { - } 1 \text { online marketing manager } \\
\text { (Expert 5) } \\
-\quad 1 \text { marketing and sales manager } \\
\text { (Expert 6) }\end{array}$ \\
\hline Hotel industry & $\begin{array}{l}1 \text { hotel director (Expert 7) } \\
-\quad 1 \text { exec. asst. hotel manager } \\
\text { (Expert 8) } \\
-\quad 1 \text { sales and marketing manager } \\
\text { (Expert 9) }\end{array}$ \\
\hline
\end{tabular}

Since innovation implementation is ultimately decided by top-level executives (Szelągowski 2019), we interviewed experts in leading positions until we reached a theoretical saturation of our analysis results (Guest et al. 2006). We selected the informants according to the snowball principle to identify the social structures in which innovations are also passed on through referrals (Robinson 2013). Moreover, we talked to two tourism digitization agencies that promote innovations and digitization in tourism destinations. We conducted these interviews from October 2019 to July 2020.

\section{Data Collection}

Expert interviews are semi-structured interviews which serve to provide structure to the research subject and guide the discussions (Trinczek 2009). In this way, the research object can be captured from the experts' perspectives, whereby the structuring element of the semi-structured interviews ensures a basis for comparing individual statements and facilitates the focusing of individual topics (Rabionet 2011). In addition, experts are suitable for this study as they already have a high level of practical experience with the research object and are therefore immensely useful for the study, in contrast to interviewees without such expertise, who, for example, quickly express speculations and wishes instead of experiences (Dorussen et al. 2005). The following list shows a selection of topics/questions used in the guide for the expert interviews:

- Definition of the term "voice search"

- Experience within the company using voice search

- Experience involving voice search (customer experience)

- Assessment of expertise in voice search

- Current activities to benefit from voice search

- Importance of voice search in tourism/touristic customer experience

- Opportunities and threats of voice search for destination management/ tourism 
The interview guide provides a framework for data collection and analysis that allows the findings and results of the different subjects to be compared (Schreier 2012).

\section{Data Analysis}

Since this study concerns the acquisition of information, qualitative content analysis is one of the most suitable approaches for data analysis (Trinczek 2009). Content analysis enables a researcher to systematically analyze and evaluate qualitative results (Mayring 2000, Schreier, 2014).

The interviews were transcribed and anonymized, and we defined categories, coding rules, and anchoring examples for data analysis. The coding process defines that the material is segmented into small units of analysis, and the individual text passages are then assigned codes or categories that assign meanings to these particular passages (Schreier 2012). These codes or categories can often be assigned to the interview questions, which are defined in the guide (Trinczek 2009). In this research, we applied an inductive method because of theoretical saturation. The data per category included the core statements.

\section{Results}

\section{Definition of Voice Search}

The experts were asked how they would define and explain the term "voice search."

All nine informants defined voice search as a voice-based search query where voice search assistants such as Siri, Alexa, or Cortana are used besides Google's voice search. In other words, one expert explains that "voice search is the conversion of an analog command into a digital one" (Expert 3). Voice search also simplifies and accelerates the online search process for any needed information as typing and haptic efforts are minimized.

\section{Voice Search Experiences}

Most of the experts reported that they have already experienced voice search in their business or private lives. However, a big gap in the level of business experience emerged; the answers ranged from "no experience" to "already tested at their touristic region." Two experts said that they had no experience with voice search, nor have they examined the premises. Two informants stated they were aware of being behind in this promising technology; however, adaptions required for voice search technology are on top of their digitization processes. Three experts owned an Echo Dot using Alexa, and they try to integrate the voice assistant into their daily life. One expert mentioned that they have observed use cases and studies; thus, the theoretical knowledge and understanding is present. However, the respondents have not yet used the technology in their touristic regions. Generally, the experts agreed that voice search technology is not yet 
widely used in the Swiss tourism industry. Only one expert stated that they have started collecting data in a structured manner to later implement a chatbot or voice search technology.

\section{Tourism Destination Expertise}

The informants who already had experience with voice search in their work were asked about the perceived expertise and skills concerning voice search within their company. All five interviewees shared that their companies were in the process of developing their voice search expertise as this knowledge has not yet been fully exploited. However, again, the level of expertise widely varied. The answers ranged from no experience to, again, only one respondent who replied that they possessed the necessary knowledge. Another expert stated that they were at an early stage and that they were trying to encourage the mind-set for new technologies within the company. Again, another expert mentioned that they try to compensate for the backlog by hiring a new person with relevant skills and knowhow. Yet another expert lamented the difficulty of being a small company with limited resources to compete with big players.

\section{Tourism Voice Search Status Quo}

As a supplementary question, we asked the informants how they assessed the status of their own company in comparison with that of the competition. The experts agreed and estimated that their knowledge of voice search in the Swiss tourism industry is rather limited. Only one informant said that their company has an advantage over their competition in voice search expertise. Two experts expressed their interest in the technology and that they are looking for partners or cooperation as their resources are limited.

\section{Efforts Made within the Organization}

Most of the experts claimed that currently no efforts are being made regarding voice search implementation in their organizations. Others have tried to introduce the subject and its relevance to service providers in workshops. One expert mentioned that they managed data on Google My Business (e.g., reviews and opening hours) as this information is also used in voice searches. Two experts indicated that they have introduced a chat platform to their customers. However, only one destination offered a chat program managed by employees during working hours, and only one expert implemented a voice bot in another touristic region.

\section{Importance of Voice Search for the Tourism Industry}

Most experts agreed that voice search will become increasingly important in the future, especially for queries such as "where is what." Local information is essential for tourism destinations and should therefore be accessible via voice 
search. For the hotel industry, voice search offers a new channel and might attract new customers. One expert said that the booking process is rather complex, and it might therefore be tedious to provide the required data and infrastructure. Moreover, two other experts added that searching for hotels might be done manually as people like to see images of the hotel and its environment. For the hospitality industry, one expert said that it might be simpler to start with restaurant opening hours than the whole booking process.

\section{Opportunities for a Tourism Destination}

Two directions emerged when we asked the respondents about voice search and destination management opportunities. On the one hand, the experts mentioned a change or effort in resources (employees). On the other hand, voice search was seen as another channel to get in touch with customers and also to differentiate from competitors. The experts indicated that voice search could lead to an optimization of or even a change in current job profiles. One expert also mentioned that the benefits of voice search strongly depend on the business model, which decides whether the technology is an opportunity or a risk.

Another expert said, "I think people are even more honest when they use voice search. I have the feeling that it is easier to speak and to formulate something, and I believe that we can analyze the search behavior even better in the background with the necessary systems than we can do now" (Expert 2). From a marketing perspective, voice search is another channel where information can be passed on to customers. Thus, it creates a new form of communication with customers. Another expert stated that the topic "voice search" should be included in the business strategy to define how to optimize voice search queries or relevant keywords. "Because I think that in voice search these keywords are probably a bit longer than if you enter them manually." Furthermore, one expert said that voice search is a simple and convenient way to access information, especially for older people. Voice search is, therefore, also an opportunity for that age group. For a younger target group, tourism providers can show that they are keeping up with the trend and are digitally ready. One interviewee also mentioned that the recommendation for a rather new technology should come from a higher-level organization. However, when the time comes, the destination should be prepared to seize the opportunity.

\section{Threats for a Tourism Destination}

The analysis of the stated risks on voice search and tourism destination management reveals three directions. The first is the issue of language, followed by questions on budget, skills, and data protection. In Switzerland, there are four national languages, and in each area, people speak a different dialect. The informants consider this problem regarding voice search integration. The question arises on which languages the content should use, and whether users will be accustomed to asking questions in standard German instead of their dialect. 
Moreover, the experts believe that in the near future, technology providers will address these language issues in voice search.

Furthermore, according to the informants, another threat is their budgets and their capacity to prepare for the technology so that it is available to users in a practical way. Thus, much time will be needed to acquire skills and manage data and availability (e.g., hotel rooms or even packages). Moreover, the order of search results and the algorithm were mentioned as well. The question of data protection or privacy also poses a risk for the experts when using voice search in a destination.

Two experts further stated that it is difficult to decide which trend or theory to follow. They also mentioned the dominance of Google as well as its impact on search results. One expert says, "I could imagine that this could simply influence opinion formation" (Expert 5). Two experts said that laziness or simplicity is encouraged for the user.

\section{Further Remarks from the Experts}

At the end of the interview, many of the informants stated that a superordinate organization would have to manage the introduction of voice assistants, and the destinations would then be the data providers. "[A destination] then takes on the role of data providers and not the role of the technology manufacturers" (Expert 1). In addition, the lack of understanding and resources to implement the digitization of destinations has been stated predominantly. Therefore, voice search is not yet an important issue in many vacation destinations or tourism providers in Switzerland, and it must first become more suitable for the masses and everyday use. Moreover, another expert said, "I am firmly convinced that in the near future, i.e., in about 35 years, the use of voice search will always more suitable for everyday use, and as soon as it reaches the masses, new business models will be created" (Expert 1).

\section{Discussion and Conclusion}

The study showed that voice search has arrived in customers' everyday life, and all experts could explain the term "voice search." However, the use of voice search in the professional environment is rather low for all interviewed experts. Especially for Swiss tourism destinations, the experts see challenges in the implementation of voice assistants. Challenges with regard to different dialects and languages are obstacles to the use of voice search for both users as well as providers from Switzerland. These challenges involving different dialects and languages in the country could also affect customers' voice experience.

Moreover, destinations often lack the resources and the necessary skills to implement and maintain such technology. Therefore, the experts revealed that partnerships or cooperation with other tourism destinations or with the umbrella organization is necessary and that players in the touristic region should maintain the required data for voice searches. It was also shown that certain tourism destinations are still at the early stages of digitization; hence, there might often be 
a lack of understanding and know-how. Some organizations, therefore, hire specialists to fill this gap.

The experts recognize the increasing importance of voice search and its application areas. However, they also think that it will be several years before the technology is suitable for the masses. In addition, the business models of the destinations need to adapt. New BMIs are expected to appear, but no concrete implementations have been made in the examined Swiss vacation destination. Also, Keiningham (2019) stated that external changes in the environment are often the drivers of BMI, which also requires modifications in the value proposition to improve the delivery of the offers to customers (Keiningham et al. 2019, Osterwalder and Pigneur 2019). Thus, value creation for customer requires more customer experience-driven thinking (Keiningham et al. 2019).

The experts also face uncertainty concerning data security and personal privacy. With the increasing use of voice bots, clear regulations are needed as there are currently none that control data collection by Apple, Google, or Facebook (Moore and Tambini 2018, Rühle et al. 2019). People are concerned that personal information is not secure or that personal data is being used without their knowledge when using digital assistants and voice-enabled technology (Olson and Kemery 2019). According to Kunath et al. (2019), users' main concern when using voice assistants is their fear of being eavesdropped.

For Swiss tourism, voice search represents an interesting opportunity to market and differentiate a travel destination or a touristic provider. It also provides another channel for contacting potential guests and informing travelers about destinations. Especially, questions such as "how do I get there" or "where is it located" are typical queries that a tourism organization has to answer. Therefore, voice search implementation would be well suited to improve guest experience.

To conclude, the qualitative study has revealed two gaps. On the one hand, the experts are monitoring and analyzing the increase in voice search usage and the resulting rise in guest expectations, but almost all the interviewed players in the destination have yet to embark on the innovation.

On the other hand, another gap was found in the expectations and acceptance of the individual players in the tourism destination. The technical implementation and the acceptance of the technology are seen as great challenges and should therefore be delegated or initiated by higher-ups, which could be the umbrella organization in this case.

Some limitations could be addressed in future studies. First, we interviewed nine experts from a vacation destination in Switzerland until we reached theoretical saturation of our analysis results (Guest et al. 2006). Future studies could extend the scope of interviews involving experts at the management level. Moreover, the focus could be shifted to hoteliers, as voice assistants are particularly suitable for use in hotels (Kattara and El-Said 2014). Additionally, guests' perspectives should be examined; therefore, future studies should interview guests regarding their expectations and acceptance of voice assistants. 


\section{References}

Amazon (2020) Amazon Alexa for hospitality. Retrieved from https://www.amazon.com/ alexahospitality. [Accessed 18 May 2020]

Amit R, Zott C (2001) Value creation in e-business. Strategic Management Journal 22(67): 493-520.

Arnould EJ, Thompson CJ (2005) Consumer culture theory (CCT): twenty years of research. Journal of Consumer Research 31(4): 868-882.

Bagozzi RP, Lee K-H (1999) Consumer resistance to, and acceptance of, innovations. ACR North American Advances 26. Provo, UT : Association for Consumer Research.

Barata M, Salman AG, Faahakhododo I, Kanigoro B (2018) Android based voice assistant for blind people. Library Hi Tech News.

Bass FM (1969) A simultaneous equation regression study of advertising and sales of cigarettes. Journal of Marketing Research 6(3): 291-300.

Belk RW, Fischer E, Kozinets RV (2013) Qualitative consumer \& marketing research. SAGE Publications.

Biondi L, Bracci E (2018) Sustainability, popular and integrated reporting in the public sector: a fad and fashion perspective. Sustainability 10(9): 3112.

Boas F (1942) Language and culture. In WG Lelan (ed), Studies in the history of culture: the disciplines of the humanities, 178-194. The George Banta Publishing Company.

Bowen J, Morosan C (2018) Beware hospitality industry: the robots are coming. Worldwide Hospitality and Tourism Themes 10(6): 726-733.

Brozovic D (2018) Strategic flexibility: a review of the literature. International Journal of Management Reviews 20(1): 3-31.

Carmel D (2019) On the relation between products' relevance and customers' satisfaction in voice shopping. Companion Proceedings of the 2019 World Wide Web Conference, 326.

Cecchinato M, Harrison D (2017) Degrees of agency in owners and users of home IoT devices. In ACM CHI 2017 Conference.

Chandler JD, Lusch RF (2015) Service systems: a broadened framework and research agenda on value propositions, engagement, and service experience. Journal of Service Research 18(1): 6-11.

Chesbrough H (2010) Business Model Innovation: Opportunities and Barriers. Long Range Planning 43(2): 354-363.

Chesbrough H, Rosenbloom RS (2002) The role of the business model in capturing value from innovation: evidence from Xerox Corporation's technology spin-off companies. Industrial and Corporate Change 11(3): 529-555.

Dorussen H, Lenz H, Blavoukos S (2005) Assessing the reliability and validity of expert interviews. European Union Politics 6(3): 315-337.

Drucker PF (2001) The essential drucker. HarperCollins Publishers.

Esser J (2019) Smart travel assistants - The new gateway for travel? Roland Berger. Retrieved from: https://www.rolandberger.com/nl/Point-of-View/Smart-TravelAssistants-The-new-gateway-for-travel.html. [Accessed 1 April 2020]

Flick U (2010) An introduction to qualitative research. SAGE Publications, Inc.

Gold B (2018) Silicon Valley start-ups and corporate innovation. Approaches to resolve the innovator's dilemma. Springer Nature.

Google Data, U.S., Google App (2016). Think with Google. Retrieved from: https://www.thinkwithgoogle.com/data/google-app-voice-search/. [Accessed 23 April 2020].

Guest G, Bunce A, Johnson L (2006) How many interviews are enough? An experiment 
with data saturation and variability. Field Methods 18(1): 59-82.

Hill J, Randolph Ford W, Farreras IG (2015) Real conversations with artificial intelligence: a comparison between human-human online conversations and humanchatbot conversations. Computers in Human Behavior 49(Aug): 245-250.

Hirschberg J, Manning CD (2015) Advances in natural language processing. Science 349(6245): 261 LP-266.

Ho SY, Bodoff D (2014) The effects of web personalization on user attitude and behavior. MIS Quarterly 38(2): 497-A10.

Hong A, Nam C, Kim S (2020) What will be the possible barriers to consumers' adoption of smart home services? Telecommunications Policy 44(2): 101867.

Hörner T (2019) Marketing mit Sprachassistenten. So setzen Sie Alexa, Google Assistant \& Co strategisch erfolgreich ein. [Marketing with voice assistants. How to use Alexa, Google Assistant \& Co strategically successfully]. Springer Gabler.

Hoy MB (2018) Alexa, Siri, Cortana, and more: an introduction to voice assistants. Medical Reference Services Quarterly 37(1): 81-88.

Hughes M, Morgan RE (2007) Deconstructing the relationship between entrepreneurial orientation and business performance at the embryonic stage of firm growth. Industrial Marketing Management 36(5): 651-661.

IDC (2018) Smart speaker market revenue worldwide in 2017, 2018 and 2022 (in billion U.S. dollars) [Graph]. Statista. Retrieved from: https://www.statista.com/statistics/ 822511/worldwide-smart-speaker-market-revenue/. [Accessed 23 April 2020]

Ivan A (2008) From technology imitation to market dominance: the case of iPod. Competitiveness Review: An International Business Journal 18(3): 257-274.

Ivanov S, Webster C (2019a) Perceived appropriateness and intention to use service robots in tourism. In J Pesonen, J Neidhardt (eds), Information and Communication Technologies in Tourism 2019, 237-248. Springer International Publishing.

Ivanov $\mathrm{S}$, Webster C (2019b) What should robots do? A comparative analysis of industry professionals, educators and tourists. In J Pesonen, J Neidhardt (eds), Information and Communication Technologies in Tourism 2019, 249-262. Springer International Publishing.

Kang M, Shin D-H, Gong T (2016) The role of personalization, engagement, and trust in online communities. Information Technology \& People 29(3): 580-596.

Kattara HS, El-Said OA (2014) Customers' preferences for new technology-based selfservices versus human interaction services in hotels. Tourism and Hospitality Research 13(2): 67-82.

Keiningham T, Aksoy L, Bruce HL, Cadet F, Clennell N, Hodgkinson IR et al. (2019) Customer experience driven business model innovation. Journal of Business Research 116(C): 431-440.

Klaus P, Zaichkowsky J (2020) AI voice bots: a services marketing research agenda. Journal of Services Marketing 34(3): 389-398.

Kreutzer RT, Seyed Vousoghi D (2020) Voice-Marketing-Journey zur Implementierung des Voice-Marketings in Unternehmen. [Voice marketing journey for implementing voice marketing in companies]. In RT Kreutzer, D Seyed Vousoghi (eds), VoiceMarketing: Der Siegeszug der digitalen Assistenten. Springer Fachmedien Wiesbaden.

Kreutzer RT, Sirrenberg M (2020) Fields of application of artificial intelligencecustomer service, marketing and sales. In RT Kreutzer, M Sirrenberg (eds), Understanding Artificial Intelligence: Fundamentals, Use Cases and Methods for a Corporate AI Journey, 105-154. Springer International Publishing.

Kumar V, Ramachandran D, Kumar B (2020) Influence of new-age technologies on marketing: a research agenda. Journal of Business Research (Jan). 
Kunath G, Hofstetter R, Jörg D, Demarchi D (2019) Voice Barometer Schweiz 2018. Switzerland: Universität Luzern.

Lee S, Choi J (2017) Enhancing user experience with conversational agent for movie recommendation: effects of self-disclosure and reciprocity. International Journal of Human-Computer Studies 103(Jul): 95-105.

Li T, Bao C, Xu W, Pan J, Yan Y (2009) Improving voice search using forward-backward LVCSR system combination. In H Wang, Y Shen, T Huang, Z Zeng (eds), The Sixth International Symposium on Neural Networks (ISNN 2009), 769-777. Springer Berlin Heidelberg.

Libai B, Muller E, Peres R (2009) The diffusion of services. Journal of Marketing Research 46(2): 163-175.

Liu D, Li Y, Thomas MA (2017) A roadmap for natural language processing research in information systems. Proceedings of the $50^{\text {th }}$ Hawaii International Conference on System Sciences.

Lodging Magazine (2016) Aloft hotels unveils voice-activated hotel rooms. Lodging Magazine. Retrieved from: https://lodgingmagazine.com/aloft-hotels-unveils-voiceactivated-hotel-rooms/.

Lovato S, Piper AM (2019) Young children and voice search: what we know from humancomputer interaction research. Frontiers in Psychology 10(Jan): PMC6349721.

Ma Z, Yang Z, Mourali M (2014) Consumer adoption of new products: independent versus interdependent self-perspectives. Journal of Marketing 78(2): 101-117.

Maggioni I, Marcoz EM, Mauri C (2014) Segmenting networking orientation in the hospitality industry: an empirical research on service bundling. International Journal of Hospitality Management 42(Sep): 192-201.

Mahajan V (2010) Innovation diffusion. In Wiley International Encyclopedia of Marketing.

Mari A (2019) Voice commerce: understanding shopping-related voice assistants and their effect on brands. IMMAA Annual Conference. Northwestern University in Qatar, Doha (Qatar), 2.

Mayring P (2000) Qualitative content analysis. Forum Qualitative Sozialforschung / Forum Qualitative Social Research 1(2): Art. 20.

McCaffrey M, Hayes P, Wagner J, Hobbs M (2018) Consumer intelligence series: prepare for the voice revolution. Technical Report.

McDermott CM, O'Connor GC (2002) Managing radical innovation: an overview of emergent strategy issues. Journal of Product Innovation Management 19(6): 424438.

Moore M, Tambini D (2018) Digital dominance: the power of Google, Amazon, Facebook, and Apple. UK: Oxford University Press.

Olson C, Kemery K (2019) Voice report. Retrieved from: https://advertiseonbingblob.azureedge.net/blob/bingads/media/insight/whitepapers/2019/04\%20apr/voic e-report/bingads_2019_voicereport.pdf.

Omerzel GD (2016) A systematic review of research on innovation in hospitality and tourism. International Journal of Contemporary Hospitality Management 28(3): 516-558.

Osterwalder A, Pigneur Y (2019) Business model generation. John Wiley \& Sons, Inc.

Pagani M, Racat M, Hofacker CF (2019) Adding Voice to the omnichannel and how that affects brand trust. Journal of Interactive Marketing 48(Nov): 89-105.

Payne AF, Storbacka K, Frow P (2008) Managing the co-creation of value. Journal of the Academy of Marketing Science 36(1): 83-96.

Perez S (2018) Voice shopping estimated to hit \$40+ billion across U.S. and U.K. by 2022. TechCrunch. Retrieved from: https://techcrunch.com/2018/03/02/voice- 
shopping-estimated-to-hit-40-billion-across-u-s-and-u-k-by-2022/.

Pikkemaat B, Peters M, Bichler BF (2019) Innovation research in tourism: research streams and actions for the future. Journal of Hospitality and Tourism Management, 41(Dec): 184-196.

Prins R, Verhoef PC (2007) Marketing communication drivers of adoption timing of a new e-service among existing customers. Journal of Marketing 71(2): 169-183.

Purington A, Taft JG, Sannon S, Bazarova NN, Taylor SH (2017) "Alexa is my new BFF": social roles, user satisfaction, and personification of the Amazon echo. Proceedings of the 2017 CHI Conference Extended Abstracts on Human Factors in Computing Systems, 2853-2859.

Rabionet SE (2011) How I learned to design and conduct semi-structured interviews: an ongoing and continuous journey. The Qualitative Report 16(2): 563-566.

Rhee CE, Choi J (2020) Effects of personalization and social role in voice shopping: an experimental study on product recommendation by a conversational voice agent. Computers in Human Behavior 109(Aug): 1-11.

Robinson OC (2013) Sampling in interview-based qualitative research: a theoretical and practical guide. Qualitative Research in Psychology 11(1): 25-41.

Rühle A, Hoesch L, Petersohn M (2019) Innovativer Einsatz digitaler Medien im Marketing [Innovative use of digital media in marketing]. L Winnen, A Rühle, A Wrobel (eds), SpringerGabler.

Russell S, Dewey D, Tegmark M (2015) Research priorities for robust and beneficial artificial intelligence. Ai Magazine 36(4): 105-114.

Ryan B, Gross NC (1943) The diffusion of hybrid seed corn in two Iowa communities. Rural Sociology 8(1): 15-24.

Rzepka C (2019) Examining the use of voice assistants: a value-focused thinking approach. Twenty-Fifth Americas Conference on Information Systems.

Saad U, Afzal U, El-Issawi A, Eid M (2017) A model to measure QoE for virtual personal assistant. Multimedia Tools and Applications 76(10): 12517-12537.

Schalkwyk J, Beeferman D, Beaufays F, Byrne B, Chelba C, Cohen M, et al. (2010) "Your word is my command": Google search by voice: a case study. In A Neustein (ed), Advances in Speech Recognition: Mobile Environments, Call Centers and Clinics, 61-90. Springer US.

Schreier M (2012) Qualitative content analysis in practice. SAGE Publications.

Schreier M (2014) Qualitative content analysis. In U Flick (ed), The Sage Handbook of Qualitative Data Analysis, 170-183). SAGE Publications.

Shankar V, Venkatesh A, Hofacker C, Naik P (2010) Mobile marketing in the retailing environment: current insights and future research avenues. Journal of Interactive Marketing 24(2): 111-120.

Silverman D (2020) Interpreting qualitative data. SAGE Publications.

Smith CA (2019) The uses of pilot studies in sociology: a processual understanding of preliminary research. The American Sociologist 50(4): 589-607.

Stebbins RA (2001) Exploratory research in the social sciences. SAGE Publications.

Szelaggowski M (2019) Dynamic business process management in the knowledge economy. creating value from intellectual capital. Springer.

Tam KY, Ho SY (2005) Web personalization as a persuasion strategy: an elaboration likelihood model perspective. Information Systems Research 16(3): 271-291.

Trinczek R (2009) How to Interview managers? Methodical and methodological aspects of expert interviews as a qualitative method in empirical social research. In A Bogner, B Littig, W Menz (eds), Interviewing Experts, 203-216. Palgrave Macmillan.

Tussyadiah I (2020) A review of research into automation in tourism: launching the annals 
of tourism research curated collection on artificial intelligence and robotics in tourism. Annals of Tourism Research 81(Mar): 102883.

Van den Bulte C, Joshi YV (2007) New product diffusion with influentials and imitators. Marketing Science 26(3): 400-421.

Vargo SL, Lusch RF (2004) Evolving to a new dominant logic for marketing. Journal of Marketing 68(Jan): 1-17.

Von der Pütten AM, Krämer NC, Gratch J, Kang S-H (2010) "It doesn't matter what you are!" Explaining social effects of agents and avatars. Computers in Human Behavior 26(6): 1641-1650.

Weis HC, Steinmetz P (2012) Marktforschung. [Market research]. NWB Verlag, Auflage: 8.

Wirtz BW, Göttel V, Daiser P (2016) Business model innovation: development, concept and future research directions. Journal of Business Models 4(1): 1-28. 
